ISSUES AND INNOVATIONS IN NURSING PRACTICE

\title{
Cancer-related pain in palliative care: patients' perceptions of pain management
}

\author{
Barbro Boström PhD RN RNIC RNT \\ Senior Lecturer, School of Social and Health Sciences, Halmstad University, Halmstad, Sweden \\ Marie Sandh MNSc RN RNAN RNT \\ Lecturer, School of Social and Health Sciences, Halmstad University, Halmstad, Sweden
}

Dag Lundberg MD PhD FRCA

Professor, University Hospital, Lund University, Lund, Sweden

and Bengt Fridlund PhD RN RNAN RNT

Professor, School of Social and Health Sciences, Halmstad University, Halmstad; and Department of Nursing, Lund University, Lund, Sweden

Submitted for publication 22 October 2002

Accepted for publication 15 September 2003

Correspondence:

Barbro Boström,

School of Social and Health Sciences,

Halmstad University,

PO Box 823,

S-301 18 Halmstad,

Sweden.

E-mail: barbro.bostrom@hos.hh.se
BOSTRÖM B., SANDH M., LUNDBERG D. \& FRIDLUND B. (2004) Journal of Advanced Nursing 45(4), 410-419

Cancer-related pain in palliative care: patients' perceptions of pain management Background. Pain is still a significant problem for many patients with cancer, despite numerous, clear and concise guidelines for the treatment of cancer-related pain. The impact of pain cognition on patients' experiences of cancer-related pain remains relatively unexplored.

Aim. The aim of this study was to describe how patients with cancer-related pain in palliative care perceive the management of their pain.

Method. Thirty patients were strategically selected for interviews with open-ended questions, designed to explore the pain and pain management related to their cancer. The interviews were analysed using a phenomenographic approach.

Findings. Patients described 10 different perceptions of pain and pain management summarized in the three categories: communication, planning and trust. In terms of communication, patients expressed a need for an open and honest dialogue with health care professionals about all problems concerning pain. Patients expressed an urgent need for planning of their pain treatment including all caring activities around them. When they felt trust in the health care organization as a whole, and in nurses and physicians in particular, they described improved ability and willingness to participate in pain management. While the findings are limited to patients in palliative care, questions are raised about others with cancer-related pain without access to a palliative care team.

Conclusion. The opportunity for patients to discuss pain and its treatment seems to have occurred late in the course of disease, mostly not until coming in contact with a palliative care team. They expressed a wish to be pain-free, or attain as much pain relief as possible, with as few side effects as possible. 
Keywords: cancer-related pain, communication, pain management, perceptions, phenomenography, planning, trust, nursing

\section{Background}

Extensive research has been carried out into cancer-related pain control and numerous clear and concise guidelines for the treatment of cancer-related pain are available [World Health Organization (WHO) 1996, The National Board of Health and Welfare 2001]. Despite the demonstrated efficiency of these approaches, cancer-related pain is not adequately managed and too many patients still suffer from unrelieved pain (Thomason et al. 1998, Sela et al. 2002). The pain experience is the end result of a complex process, one that occurs at various levels. Cognitions, such as patients' interpretations of symptoms and what the symptoms mean, are the most important areas to explore (Calvin et al. 1999). A probable result of not exploring these cognitions is patients' reluctance to report pain and decision not take medication despite knowing it to be effective. The impact of pain cognition on patients' experiences of cancer pain remains relatively unexplored.

\section{Literature review}

The physical causes of cancer pain are diverse, since cancer can originate from multiple sites throughout the body as well as from therapies and procedures such as surgery, radiation and chemotherapy (Twycross et al. 1996, Twycross 1997). In order to understand and appropriately treat a pain-suffering patient an accurate assessment is required, not only of tissue damage that may have caused pain, but also of specific sociocultural, behavioural and affective factors contributing to pain. If this multidimensionality of pain is not taken into account patients' attempts to communicate pain may be unsuccessful. The process of pain management also includes optimal use of pain treatment. This requires that patients and health care professionals have adequate knowledge of basic pain principles and that they overcome misconceptions and inappropriate beliefs. Ultimately, not reporting pain and not using analgesics can contribute to poor pain management for many patients (Ward et al. 2000). However, these concerns are not isolated phenomena: they stem from how patients perceive their whole situation, and particularly from how they perceive the health care organization (Ashby \& Dowding 2001). Qualitative studies in general show the importance of contact, communication and active assessment of pain (Simonsen-Rehn et al. 2000), and of managing pain in the earlier stages of the disease in order to address barriers to analgesic use [American Pain Society (APS) 1995, Ersek et al. 1999]. Studies also show that health care professionals must encourage and recognize patients' thoughts, beliefs and methods of handling pain, since these all influence pain treatment. Successful pain management is not accomplished without an open and honest dialogue (Ashby \& Dowding 2001). Sjöström et al. (2000) found, when using a phenomenographic approach, that nurses perceived difficulties in assessing patients' pain. However, no research with the phenomenographic approach to investigate patients' perceptions of pain management has been found, regarding either acute pain or cancer-related pain. As there seem to be patientrelated barriers to pain control (Gunnarsdottir et al. 2002) health care professionals need to gain an understanding of the role of pain cognitions. By using patients' own experiences as a standpoint, appropriate care interventions can be introduced (Sjöström et al. 2000).

\section{The study}

\section{Aim}

The aim of this study was to describe how patients with cancer-related pain in palliative care settings perceive management of their pain.

\section{Design}

The focus of this explorative and descriptive study was on patients' perceptions of pain and pain management, therefore a phenomenographic approach was chosen. The ultimate purpose of phenomenographic research is to show how something is perceived to be: a way of experiencing something (Marton 1981, Marton \& Booth 1997). A distinction is made between the first-order perspective which starts with facts that can be observed externally - how something 'really is', and the second-order perspective which starts with the person's experiences or how things appear to the person. Phenomenography describes perceptions using the secondorder perspective. It is effective for describing the qualitative variations of people's perceptions of their surroundings, for example, how they think, conceptualize, understand and remember various aspects of a phenomenon (Marton \& Booth 1997). In this study, their pain management is the phenomena. In phenomenography, perceptions constitute the frame of reference within which knowledge is gathered, and 
the foundation on which reason is built. Phenomenography and phenomenology have certain features in common, but a main difference is that phenomenography is substanceoriented whereas phenomenology is primarily methodological and/or philosophical. While the essence of phenomenology is to understand 'what' people experience, the essence of phenomenography is to describe 'how' people perceive.

\section{Sample}

Patients with diagnosed cancer receiving care from two hospital-based palliative care teams in a health care and medical county council in southwest Sweden were included in the study. Inclusion criteria were being oriented to person and place, having no major sensory defects, able to speak Swedish, in need of analgesic treatment and with one of the following diagnoses: lung cancer, colorectal cancer, breast cancer or prostate cancer. In addition, patients needed to be aware that they had been diagnosed with cancer and would receive palliative care, as opposed to primarily curative care. In order to ensure as broad a selection as possible (Fridlund \& Hildingh 2000) patients were strategically chosen with regard to the following criteria: gender, age, marital status, diagnosis, duration of care from a palliative care team, and place of care (Table 1). A sample of 30 patients was judged to be suitable, considering that the patient group was vulnerable and had limited ability and strength for long interviews.

\section{Data collection}

Open and semi-structured interviews constitute the basis for gathering data when using a phenomenographic approach. The patients decided the time and place for the interviews, 20 patients were interviewed in their homes and 10 at hospital. Interviews lasted between 30 and 90 minutes and were audio taped and transcribed verbatim. The interview plan consisted of preliminary questions intended to introduce a number of delimited phenomena within the fields of physiological, sensory, affective, cognitive, behavioural, and socio-cultural dimensions of pain management related to cancer (Ahles et al. 1983, McGuire 1992, Ferrell et al. 1994, Strang 1998). The following preliminary questions formed the basis of the conversational interviews: Tell me, what is pain for you? How does pain affect you? Tell me about your treatment for pain relief. What has it been like? Treatment other than analgesics, what about that? Tell me, about your own strategies for reducing pain? How do you perceive your own ability to participate in your pain treatment? How do you perceive the information you have received from health care professionals about your pain and its treatment? What
Table 1 Demographic and clinical characteristics of patients $(n=30)$

\begin{tabular}{lr}
\hline & $n$ \\
\hline Gender & \\
Male & 17 \\
Female & 13 \\
Age (years) (range: 35-83) & 9 \\
35-65 & 21 \\
66-83 & \\
Civil status & 23 \\
Married or cohabiting & 7 \\
Single & \\
Diagnosis & 7 \\
Colorectal cancer & 7 \\
Breast cancer & 7 \\
Lung cancer & \\
Prostate cancer & 20 \\
Place of care & 10 \\
At home & \\
In hospital & 18 \\
Time with palliative care team (months) & 12 \\
1-3 & \\
4-6 & 30 \\
Analgesics & 18 \\
Strong opioid & 25 \\
Non-steroidal anti-inflammatory drugs & \\
Paracetamol & \\
\hline
\end{tabular}

about the environment that you have encountered, how do you see it?

\section{Ethical considerations}

The study was approved by the Committee of Ethics in Medical Investigations, Universities of Lund and Göteborg, Sweden. Patients were written to and verbally informed of the study, and the staff of the palliative care teams asked if they were willing to participate. When the patients had agreed, the main author contacted them in order to collect the data. Patients were informed that participation in the study was voluntary; that answers would be treated in confidence and that they could withdraw from the study at any time without giving a reason. The main author (who collected the data) had no connection with the palliative care teams; neither did the co-authors.

\section{Data analysis}

The analysis was performed with collaboration between the main author and two of the co-authors, all three of whom have high competence in pain and/or qualitative research, and involved the following stages. 
Table 2 Categories, perceptions and expressions of pain management

\begin{tabular}{|c|c|c|}
\hline Categories & Perceptions & Expressions (patient number) \\
\hline \multirow[t]{9}{*}{ Communication } & \multirow{3}{*}{ Aching all over } & Pain influences the behaviour (patients: $4,7,13,18,21,22,26,28,29,30$ ) \\
\hline & & Pain can be expressed with emotions (patients: $3,4,7,14,16,18,19,22-26,28$ ) \\
\hline & & Pain can be expressed as sensations from the body (patients: $11,14-18,20-26,28-30$ ) \\
\hline & \multirow{3}{*}{$\begin{array}{l}\text { Ability to talk about } \\
\text { aches and discomfort }\end{array}$} & Being believed (patients: $1,4,7,14,28-30$ ) \\
\hline & & Seeing the whole person (patients: $18,25,30$ ) \\
\hline & & Using the right tool (patients: $8,18,19,26,28,30$ ) \\
\hline & \multirow[t]{3}{*}{ Freedom from pain } & Gaining from pain relief (patients: $1,2,4,5,12,14,22,26,27,30$ ) \\
\hline & & Interpretation of pain (patients: $1,10,13,14,22,25-30$ ) \\
\hline & & Influence from personality (patients: $1,3,4,8,13,15,17,18,22,28-30$ ) \\
\hline \multirow[t]{9}{*}{ Planning } & \multirow[t]{3}{*}{ Taking drugs is unavoidable } & Large amount of different drugs (patients: $4,14,15,17,19,20,24,25,28$ ) \\
\hline & & Around the clock (patients: $1,4,7,8,11,12,14,16,17,23,28$ ) \\
\hline & & Information need (patients: $1,2,4,5,7,11,14,17,19,20,22,25,27,29$ ) \\
\hline & \multirow{2}{*}{$\begin{array}{l}\text { Uncertainty concerning non- } \\
\text { pharmacological treatment }\end{array}$} & Staff's recommendations (patients: $4,7,10,13,17,18,23,25,29,30$ ) \\
\hline & & Patients' attitudes (patients: 4, 7, 10, 11, 17, 18, 23, 24, 29) \\
\hline & \multirow[t]{2}{*}{ Pain killer causing trouble } & Problematic side-effects (patients: $1,4,5,8,11,14,17,18,20,22-26,29$ ) \\
\hline & & Fear of side-effects (patients: $13,15,17,23,25,28$ ) \\
\hline & \multirow[t]{2}{*}{ Suffering from caring actions } & Pain from treatment (patients: $1-4,8,23,25,26,29,30$ ) \\
\hline & & Waiting for treatment (patients: $2,4,5,12,16,22,23,25,26,28-30$ ) \\
\hline \multirow[t]{7}{*}{ Trust } & \multirow[t]{3}{*}{ Need for humanity } & $\begin{array}{l}\text { Depending on the organization (patients: } 1,3-5,7,8,11,12,14,16,18,20,22,23 \text {, } \\
26,28,30)\end{array}$ \\
\hline & & Being treated politely (patients: $1,4,5,14,17,24-26,28-30$ ) \\
\hline & & Depending on who you meet (patients: $1-5,7,14,17-19,26,28$ ) \\
\hline & \multirow[t]{2}{*}{ Necessity of own initiative } & Being an active part in the care (patients: $1,3,4,10,17,19,22,26,27,29,30$ ) \\
\hline & & Taking responsibility for care (patients: $4,10,16,26,28$ ) \\
\hline & \multirow[t]{2}{*}{ Personal painkilling tricks } & Keeping spirit up (patients: $4,23,28$ ) \\
\hline & & Own activities (patients: $4,10,11,16-18,22,23,25,27-30$ ) \\
\hline
\end{tabular}

- Each interview was processed by locating the patient's descriptions of their perceptions of pain and pain management, as stated in the study aim. A total of 632 quotes were identified, expressing perceptions of pain and pain management, and saturation was reached after 10-15 interviews had been analysed. However, due to the strategic nature of the sample and the occurrence of short interviews resulting from patients' weak condition, all 30 interviews were analysed. This number of patients was adequate in order to reach a broad understanding of how they perceived pain and pain management.

- The analysis entailed comparisons of different descriptions to identify similarities and differences, in relation to the study aim.

- In order to gain an overall picture of how these similarities and differences could be connected, they were grouped into patterns with common features.

- These patterns were carefully examined in order to detect dimensions in the answers, in which new formulations and categories were needed to describe perceptions.

- The outcome space (Wenestam 2000) constituting the description categories and perceptions was further examined to ensure consistency. Finally, perceptions with representative descriptions and quotes were formed into three description categories (Table 2).

The accuracy of the study is guaranteed, as all interviews were performed by one interviewer and transcribed verbatim with quotes shown (Fridlund \& Hildingh 2000). The reasonableness of the study is increased by two factors: the main author and two co-authors - competent in the field of pain and pain treatment - evaluated the questions, and saturation of the perceptions was reached before all interviews had been performed. The trustworthiness of the study is confirmed by the three authors' analysis and discussion of the interviews. A systematic, methodological and reflective approach was applied in order to check the accordance of categories, perceptions and expressions.

\section{Findings}

\section{Communication}

This category included the perceptions Aching all over, Ability to talk about aches and discomfort and Freedom from 


\section{B. Boström et al.}

pain, all describing the need for an open and honest dialogue between patients and health care professionals about all the patients' pain-related problems. A need to improve verbal communication and understanding of the patients' nonverbal communication was apparent. Lack of communication prevented patients from being believed and from being able to discuss things like dreams, previous experiences, and their knowledge, fears and learned behaviour about pain. When communication worked effectively, patients perceived an increased understanding of their pain, as well as of problems concerned with treating their pain.

The perception Aching all over summarizes patients' descriptions of pain and showed that there were several ways of expressing the acute pain they had felt and sometimes continued to feel. Expressions included in this perception were:

\section{Pain influences the behaviour:}

There have been times when I haven't been able to stand or sit...Coughing has been impossible...Pain affects me so that I am frightened to do anything.

If you are in pain then you are in a bloody boring mood - don't want to do anything. If you are not in pain then you are happy.

Pain can be expressed with emotions:

Living hell it's unbearable and it makes you wonder what comes after 10 [on VAS].

It's terrible, unbearable and horrible. It's also frightening because it hurts so much.

Pain can be expressed as sensations from the body:

Like thousands of needles are being stuck in me here and 'specially on my hip.

Then it's gnawing at me all the time and aching.

The perception Ability to talk about aches and discomfort describes patients' expressions of problems they have experienced in conjunction with having pain assessed. The need for frequent assessment of pain was shown, including all expressions of pain and using the patient's self-report along with adequate measuring tools. Expressions included in this perception were:

Being believed:

I was in so much pain so I went in by ambulance and yet they said it was psychosomatic! It turned out to be a relapse. They are poor communicators, I have thought this the whole time. I still believe that patients' input can be a big help, it is after all the patient who knows her body best.
He believed me with just a few simple words.

Seeing the whole person:

Since the body is a whole, I think that they are working very much with isolated parts of the body. It's as if they weren't connected.

Using the right tool:

I feel as though if I am in pain then I have to use that to show it (Visual Analogue Scale). I have to be able to show them how much it hurt before and how much it hurts now. I can't just sit and explain what it's like with words.

The perception Freedom from pain describes patients' overall wish to experience freedom from pain or to have as much pain relief as possible and their interpretations of the consequences of pain. Patients talked about the benefits of pain relief and were aware that their personality and attitudes to analgesics constituted an influence over the quality of pain relief. They also expressed a wish for an early and ongoing discussion about their pain and pain relief. Expressions included in this perception were:

Gaining from pain relief:

I couldn't understand it was true, I just lay and enjoyed not having it. To be rid of this problem was paradise. It was an experience in and of itself.

If I can just be rid of pain then I want to have as much as I can get.

Interpretation of pain:

If I have a certain dose which works and then the pain returns, then it must be because the disease has got worse but the longer the pain carries on the more difficult it is to stop it.

The disadvantage of pain for the body is that all energy is used to work on the pain, so resistance gets reduced.

Influence from personality:

Then I think it has to do with how you are brought up too, I know, I think of dad - there it was necessary to have a high pain threshold throughout his life, you should be able to withstand pain.

\section{Planning}

This category included the perceptions Taking drugs is unavoidable, Uncertainty concerning non-pharmacological treatment, Painkiller causing trouble, and Suffering from caring actions, all of which describe the urgent need for structured planning of all caring actions around the patient. A need to discuss and plan for pain treatment earlier in their course of disease was made clear. The patients were more 
positive toward analgesics once planning and information about their pain treatment had improved. This had mostly not occurred until patients started receiving care from a palliative care team.

The perception Taking drugs is unavoidable describes the patients' expressions of the different medication routines they had gone through. Expressions included in this perception were:

Large amount of different drugs:

I received a lot of tablets - nerve tablets for my back, and Panodil [Paracetamol] was a part of the prescription. I ate Artrotec [nonsteroid-antiinflammatory drug], it was a whole bloody mountain of tablets.

Around the clock:

So I was given a note telling me exactly how I should take them, at 7 , 3 and 11 o'clock. Then I had morphine tablets, a dose for safety's sake.

Once the palliative team got the right balance of these capsules they've been very good...really nice to be rid of the pain.

Information need:

Doctor just wrote me a prescription and told me it was a painkiller I could take when I needed. When I arrived at the chemist they asked me for identification and told me it was morphine.

Now we learned, one should take tablets all the time...build up the pain-relief, so to speak.

The perception Uncertainty concerning non-pharmacological treatment describes how patients - and as they perceived it, even health care professionals - had limited knowledge of the effects of planning interventions such as radiation therapy, transcutaneous nerve stimulation, massage, and acupuncture. Expressions included in this perception were:

Staff recommendations:

She suggested TENS and acupuncture...I should take it when I feel pain.

Patients' attitudes:

One thought when one received this radiation treatment that it would get everything, admittedly it has but I thought it would be even better.

The acupuncture...seems good. I believe there is something in it, actually.

The perception Painkiller causing trouble showed that patients expressed fear of side effects, especially from morphine. Some had experienced so many problems with constipation, nausea, vomiting, dizziness, fatigue, and dry mouth that they were reluctant to take further analgesics. Expressions included in this perception were:

Problematic side-effects:

I have been constipated, it's not much fun I'll tell you...I was in pain at the time. That can be very painful in any case.

Fear of side-effects:

As long as I don't destroy my kidneys, that's what I think about. Because I never ate tablets before.

I was given morphine...thought I would stop - it's a drug for god's sake. But they say that as long as you are in pain you won't be addicted.

The perception Suffering from caring actions describes how pain could emerge from different treatment actions or procedures related to the disease, such as radiation therapy, waiting for investigations, or being under consideration. Expressions included in this perception were:

Pain from treatment:

The radiation therapy was terrible

One doesn't talk about the risk of treatment.

Waiting for treatment:

They were very busy in emergency and I just lay there for five hours and hurt, but none of the doctors had the time...

The worst thing is waiting without being given a date, but if I have a fixed date it doesn't matter if it's one month away or two.

\section{Trust}

This category included the perceptions Need for humanity, Necessity of own initiative, and Personal pain killing tricks, all describing patients' need to trust themselves as well as to trust the health care organization as a whole, and nurses and physicians in particular (whom they perceived they were extremely dependent upon). When patients felt a lack of trust in the health care organization and in health care professionals, their opportunity for self-determination decreased. When they felt trust, they described a feeling of security and improved ability and willingness to participate in pain management.

The perception Need for humanity describes how patients' feeling of security and pain relief improved when they received care from a palliative care team, continuity of 


\section{B. Boström et al.}

contact with the physician, and immediate help in the hospital. Concerning health care professionals, patients described a range of important matters, such as being treated kindly, meeting engaged and competent nurses and physicians, and receiving honest and truthful information. Expressions included in this perception were:

Depending on the organisation:

If anything happens to me then I can go directly to the department, then one doesn't have to go babbling and moaning about everything again. It's so difficult when they don't know who you are.

Now with the palliative team you can get help with everything and it's a security that would be helpful everywhere, that everyone should get.

Being treated politely:

One thing that's missing in health care is the lack of respect. It's lacking on a humanitarian level. Technically they are very capable...but it's people they work with.

Once a little doctor asked how I was feeling. Nobody cares. This little one was the only one who was a bit psychological and then things turn right.

Depending on who you meet:

So I admire the nurse that I find to be very competent...sat down on the edge of the bed and gave me all the time I needed.

When I was in that much pain...thought I was going to die with this cancer, doctors are powerless...then I met the palliative care team, then I saw things from a new angle, why should I need this when I could just as well be at home with my children?

The perception Necessity of own initiative describes the patients expressed their ability and/or willingness to be selfdetermined but also a fear of being forced to take too much responsibility. Expressions included in this perception were:

Being an active part in the care:

It is difficult to influence if you don't know what you should influence. You don't know what the possibilities are.

Taking responsibility for care:

You don't get anything if you are silent.

I was given aid all the time - as soon as I had pain and said so. That's how I managed.

The perception Personal pain killing tricks describes the tricks patients reported having, for reducing their pain. They expressed a need to trust in themselves when developing tricks for pain relief. Expressions included in this perception were:

Keeping spirit up:

One believes that one is going to get better, one has to keep one's mood up as much as possible, so as not to be broken down. Yes, I dare not think too much, I don't dwell on it.

One has to teach oneself even how it feels. One has to teach oneself, how to cope with it and tackle this miserable disease.

Own activities:

It gets better if I go out hiking... but you can't hike all night.

Aqua therapy, 20 minutes in a hot bath then 10 seconds in cold water, I've tried that.

\section{Discussion}

\section{Methodological considerations}

The aim of this study was to describe how patients with cancer-related pain perceived their pain and its management. The qualitative approach of phenomenography was chosen, and proved appropriate since the study aim was achieved and the findings led to three concrete categories with representative perceptions and underlying expressions and quotes both meaningful and of clinical value (Marton \& Booth 1997) for health care professionals in improving pain management. The reasonableness of the results was increased as several patients expressed most of the perceptions.

\section{Study limitations}

It is important to point out that patients included were from one geographic region in Sweden and all received care from palliative care teams, which can be seen as a limitation of the study.

\section{Considerations for cancer-related pain management}

Three overall categories; communication, planning and trust, were identified from the interviews. These are also the cornerstones for successful pain management, as systematic gaps particularly in communication and continuity often underlie inadequate pain treatment (APS 1995).

\section{Communication}

Patients expressed a wish to be free from pain, but they also expressed doubt that this might be possible, while some were convinced that pain was a part of their disease. One unique 
aspect of cancer-related pain is the fear that pain indicates disease progression. This is not an irrational fear since pain may, in fact, be a symptom of the spread of disease (Twycross 1997). However, there were no signs of equality between the variability of pain and the variability of disease, and therefore a disparity between the person's interpretation of the significance of their pain and their actual physical condition may exist (Weiss et al. 2001). This means that health care professionals should try to understand the meaning of pain for each patient. It also stresses the need to see and differentiate when assessing pain (Simonsen-Rehn et al. 2000, Sjöström et al. 2000). Patients perceived that they had not been believed when they complained of pain. This was despite the fact that both patient and physician knew of the cancer diagnosis and that their pain expressions included all the signs of acute pain, mostly nociceptive but also with features of neurogenic pain (Twycross 1997, Duggleby 2000). Patients expressed pain in many different ways, probably in order to make it endurable and find a way to deal with it. There is no 'right way' to express pain, and this challenges health care professionals to interpret patients' pain signals. It seems that both patients and health care professionals are asked to assess and monitor signals of pain without being sure about what to look at (Tearnan \& Ward 1992). A plausible explanation may also be that both patients and health care professionals instinctively, or due to lack of knowledge, deny that the pain as caused by the cancer (Turk \& Okifuji 1999). However, whatever explanation there is, inadequate communication often contributes to suboptimal pain management, while more favourable opinions about pain management make patients more willing to ask for analgesics and more likely to be satisfied with their overall experience of health care (Calvin et al. 1999). The findings showed that patients would like to have the opportunity to discuss their pain and the available pain treatment. There were patients for whom this discussion had occurred extremely late in the course of their disease, when they were first in contact with a palliative care team, and this is too late (APS 1995).

\section{Planning}

Patients were aware of their need for analgesics but expressed lack of knowledge about possible treatment alternatives and well-structured plans. During the course of their disease there were some who had been offered many different types of analgesics and were just told to take them 'when needed'. This lack of planning and information continued often until they came into contact with a palliative care team. Patients want to make their own decisions, but this is impossible when they do not know what treatment they are having, what is available, what they will gain from it or how to take it. There were patients who had experienced side effects, usually constipation from opioids, and this was so painful that they were afraid of taking further analgesics. This is in line with previous work by Thomason et al. (1998), who found that far too often pain medication made patients 'feel bad'. The occurrence of procedure-related pain is a further discomfort. By forming and continually evaluating a treatment plan, pain relief can be optimized and side effects minimized. Several treatment plans are available, with interventions aimed to interrupt the pain pathways and/or prevent further pain and to support the patient both emotionally and socially (WHO 1996, The National Board of Health and Welfare 2001). Therefore, there is an urgent need to apply treatment plans throughout a patient's entire course of disease (APS 1995, Ersek et al. 1999). This challenges health care professionals to let patients take an active part in the planning in order to personalize both pharmacological and non-pharmacological treatments.

\section{Trust}

The findings show that patients are well aware that pain treatment directives depend on which health care professional they meet, as well as upon themselves. The desire for self-determination is somewhat conflicting as there were patients for whom having to decide about pain treatment interventions came as a burden. Others, however, expressed a frustration over not being able to make their own decisions, due to insufficient information and the feeling of being an object - not a person - in the health care environment. As pain treatment had often failed during the course of their disease, there were patients who had lost confidence in health care professionals and even ceased to believe that pain relief was achievable. Each acute pain episode they had gone through may have elevated their levels of frustration and increased the physical-sensory pain (Sela et al. 2002), contributing to difficulties with improving pain relief later in the course of cancer. Lack of knowledge and skill concerning pain management among health care professionals may still be the reason for not taking pain seriously (Strang 1998). Although patients believe in their own ability, they express a strong need for support, someone to call upon, and someone to trust and discuss with (Ersek et al. 1999). There were patients for which this was not accomplished until they came in contact with a palliative care team. Interventions aimed at increasing patients' knowledge of pain management may improve self-determination and help them to interact effectively with health care professionals. This in turn may improve pain relief for patients (Oliver et al. 2001). 


\section{What is already known about this topic}

- Many patients with cancer-related pain still suffer from treatable pain.

- A number of guidelines for effective pain relief have been published.

- Nevertheless, there are still patient- and staff-related barriers to good pain control.

\section{What this paper adds}

- It confirms that patients wish to be pain-free, or attain as much pain relief as possible, with as few side-effects as possible.

- It highlights that pain has to be assessed and discussed early in the patient's course of disease.

- It identifies communication, planning and trust as fundamental concepts for perceived pain control for patients with cancer-related pain.

\section{Implications for practice and research}

Educational interventions about pain and treatment should occur immediately after diagnosis, and pain should be recognized and treated promptly, using one of the available guidelines. By asking patients to rate their pain with VAS from the beginning, pain becomes visible and therefore easier to discuss. As nurses often have the closest contact with patients, they are the ones who can have greatest impact on their adherence to treatment plans, while developing patients' roles in treatment decisions. Patient's ideas, beliefs and experiences regarding pain and analgesic treatments must be explored. Furthermore, patients must be believed if educational interventions are to be successful, resulting in effective pain management from the beginning.

Further research is needed to explore how cancer patients without care from a palliative team perceive their pain management. There is also a need to examine health care professionals' reluctance to seriously assess patients' cancerrelated pain from the beginning of the disease, as well as to adhere to available guidelines and treatment plans.

\section{Conclusion}

When patients' perceptions of cancer-related pain management in this phenomenographic study were explored, three descriptive categories emerged: communication, planning and trust. Patients expressed a wish to be free from pain or attain as much pain relief as possible. The need for mutual, honest and ongoing discussions and interpretations of pain and its treatment - early in the course of disease - became obvious. There were some for whom this discussion seemed to have first occurred when they met the palliative care team. Patients perceived that not being believed and not having their pain assessed were critical factors leading to increased pain. Failure in developing pain treatment plans with minimum side effects also contributed to increased pain.

A trusting relationship with nurses and physicians, including the opportunity to discuss thoughts and beliefs concerning pain and its treatment, was perceived as fundamental for optimal pain control.

\section{References}

Ahles T.A., Blanchard E.B. \& Ruckdeschel J.C. (1983) The multidimensional nature of cancer pain. Pain 17, 277-288.

American Pain Society (APS) Quality of Care Committee (1995) Quality improvement guidelines for the treatment of acute pain and cancer pain. The Journal of the American Medical Association 274, 1874-1880.

Ashby M.E. \& Dowding C. (2001) Hospice care and patients' pain: communication between patients, relatives, nurses and doctors. International Journal of Palliative Nursing 7, 58-67.

Calvin A., Becker H., Biering P. \& Grobe S. (1999) Measuring patients opinion of pain management. Journal of Pain and Symptom Management 17, 17-26.

Duggleby W. (2000) Elderly hospice cancer patients' descriptions of their pain experiences. American Journal of Hospice and Palliative Care 17, 111-117.

Ersek M., Miller Kraybill B. \& Du Pen A. (1999) Factors hindering patients' use of medications for cancer pain. Cancer Practice 7, 226-232.

Ferrell B., Ferrell B., Ahn C. \& Tran K. (1994) Pain management for elderly patients with cancer at home. Cancer 74, 2139-2146.

Fridlund B. \& Hildingh C. (2000) Health and qualitative analysis methods. In Qualitative Research Methods in the Service of Health (Fridlund B. \& Hildingh C., eds.), Studentlitteratur, Lund, pp. 1325.

Gunnarsdottir S., Donovan H.S., Serlin C., Voge S. \& Ward S. (2002) Patient-related barriers to pain management: the barriers questionnaire II (BQ-II). Pain 99, 385-396.

McGuire D.B. (1992) Comprehensive and multidimensional assessment and measurement of pain. Journal of Pain and Symptom Management 7, 312-319.

Marton F. (1981) Phenomenography-describing conceptions of the world around us. Instructional Science 10, 177-200.

Marton F. \& Booth S. (1997) Learning and Awareness. Lawrence Erlbaum Associates Publishers, Mahwah, NJ.

Oliver J.W., Kravitz R.L., Kaplan S.H. \& Meyers F.J. (2001) Individualized patient education and coaching to improve pain control among cancer outpatients. Journal of Clinical Oncology 19, 2206-2212.

Sela R.A., Bruera E., Conner-Spady B., Cumming C. \& Walker C. (2002) Sensory and affective dimensions of advanced cancer pain. Psych-Oncology 11, 23-34. 
Simonsen-Rehn N., Sarvimäki A. \& Sandelin Benkö S. (2000) Cancer patients' experiences of care related to pain. Nursing Science and Research in the Nordic Countries 57, 4-9.

Sjöström B., Jakobsson E. \& Haljamae H. (2000) Clinical competence in pain assessment. Intensive and Critical Care Nursing 16, 273-282.

Strang P. (1998) Cancer Pain - A provoker of emotional, social and existential distress. Acta Oncologica 37, 641-644.

Tearnan B.H. \& Ward C.H. (1992) Assessment of the terminally ill patients with pain: the example of cancer. The Hospice Journal 8, 49-71.

The National Board of Health and Welfare (2001) Pain Management in the End of Life. Guidelines. Socialstyrelsen, Stockholm (in Swedish).

Thomason T.E., Bernard S.A., Winer E.P., Tremont S. \& Lindley C.M. (1998) Cancer pain survey: patient-centered issues in control. Journal of Pain and Symptom Management 15, 275-284.

Turk D.T. \& Okifuji A. (1999) Assessment of patients' reporting of pain: an integrated perspective. The Lancet 353, 1784-1788.
Twycross R. (1997) Cancer classification. Acta Anaesthsiologica Scandinavica 41, 141-145.

Twycross R., Harcourt J. \& Bergl S. (1996) A survey of pain in patients with advanced cancer. Journal of Pain and Symptom Management 12, 273-282.

Ward S., Donovan H.S., Owen B., Grosen E. \& Serlin R. (2000) An individualized intervention to overcome patient-related barriers to pain management in women with gynaecologic cancers. Research in Nursing and Health 23, 393-405.

Weiss S.C., Emanuel L.L., Fairclough D.L. \& Emanuel E.J. (2001) Understanding the experience of pain in terminally ill patients. The Lancet 357, 1311-1315.

Wenestam, C.G. (2000) The phenomenographic method in health research. In Qualitative Research Methods in Service of Health (Fridlund B. \& Hildingh C., eds), Studentlitteratur, Lund, pp. 97115 .

WHO (1996) Cancer Pain Relief: With A Guide to Opioid Availability, 2nd edn. World Health Organization, Geneva. 